\title{
Assessment of Safety Culture in Global Offshore Environments
}

\author{
Jagadeesh Kilaparthi \\ Department of Geography, Environment and Society, Coventry University, Coventry, UK \\ Email: jagadeeshkilaparthi1@outlook.com
}

Received 19 May 2014; revised 15 June 2014; accepted 12 July 2014

Copyright (C) 2014 by author and Scientific Research Publishing Inc. This work is licensed under the Creative Commons Attribution International License (CC BY). http://creativecommons.org/licenses/by/4.0/

c) (i) Open Access

\section{Abstract}

This project aims at presenting detailed assessment of health and safety culture in global offshore environments. Such assessment will be then utilized for developing and recommending a model capable of integrating safety behaviour and culture in global offshore environments. The global offshore environment is a quite wider term and therefore underlying study has specified and narrowed it down to the oil and gas industry. In other words, the discussion of health and safety culture is done in light of oil and gas industry and its environment. The proposed model "incident-free and low-risk contracting model" aims at fostering health and safety culture in oil and gas environments. It is worth mentioning that implementation of model requires effective support and collaboration between trade unions, industry associations, employers, and government agencies. The objectives of the proposed model will be identified in terms of Fostering sound leadership, Gaining management commitment, Gaining support and involvement of workforce, Reducing risk instances, Accident reduction objective.

\section{Keywords}

Health and Safety Culture, Offshore Environment, Oil and Gas Environment

\section{Introduction}

The concept of health and safety culture is not a new phenomenon in business world. It has been developed and evolved since last many years. However, the concept has gained significant recognition and attention in recent years. This is due to regulatory pressure, workforce empowerment, need of avoidance of legal litigations and developing sustainable working environment (Lowe 2008) [1]. All business organisations irrespective of their nature, scope and size of operations have started assigning high importance to safety and health related issues. As a result, the concept of health and safety is being cultivated in the overall culture and philosophy of business 
organisations. The strategies authorities across the world also affirm the fact that health and safety culture is one of highest priority area of business operations in the present time and will continue in the future also (Perry 2003) [2].

The health and safety culture can be defined as an aggregation of beliefs, attitudes, and values that contribute and facilitate hygiene behaviour and environment in a business setting. The concept of health and safety culture is treated and recognised as a shared concept as it seeks involvement of all organisation members. Although the phenomenon of health and safety culture is conceptualised by higher authorities or top managers of business firms, yet it depends on general workforce for its implementation. The most evident impact of health and safety culture is the reduction in the number and frequency of accidents and other hazards. This impact can also be understood in terms of a reason or factor leading business organisations to develop strong health and safety cultures (Ariss 2003) [3].

In this context, the underlying project aims at presenting detailed assessment of health and safety culture in global offshore environments. Such assessment will be then utilised for developing and recommending a model capable of integrating safety behaviour and culture in global offshore environments. The global offshore environment is a quite wider term and therefore underlying study has specified and narrowed it down to the oil and gas industry. In other words, the discussion of health and safety culture is done in light of oil and gas industry and its environment.

\subsection{Research Aim}

The aim of the underlying project is to develop a model that integrates safety behaviour and culture in oil and gas environments. Such proposed model should be capable and effective enough in reducing risky instances and providing a safe and secure environment to organisation's personnel.

\subsection{Objectives}

The other objectives of the project in light of above discussed aim are as follow:

- To explore the concept of health and safety culture in context of oil and gas environment.

- To analyse the role of organisation in implementing and maintaining safety culture in oil and gas industries.

- To discuss the nature of oil and gas environment and as well as trends of safety culture in the selected environment.

- To throw light on the challenges and barriers fostering in the implementation of health and safety culture in specific context of oil and gas environment.

- To elaborate theoretical concepts of safety culture with the help of some academic theories and models.

\section{Literature Review}

The concept of health and safety culture has been explored more deeply in this section of the project. As mentioned in the proposal, secondary sources like academic publications, journal articles, books, research reports, etc are utilised for this purpose. The various sub-sections of the literature review are:

\subsection{Health and Safety Culture}

The concept of health and safety culture has been explained and positioned by different authors and researchers in different dimensions. Like, some authors and research works have termed and identified the concept of health and safety culture as a process, belief or ideology while some others have identified it in terms of system and mechanism of retaining human resource (Fishback \& Kantor 2007) [4]. This section of the literature review has made an attempt to explore maximum possible dimension of health and safety culture in order to gain deep insight regarding it.

According to Stranks (2006) [5], health and safety culture should be understood in term of a framework consisting wide variety of multi-dimensional elements. The author has identified six main dimensions in the framework of safety culture of oil and gas industry. It is said that all these six dimensions are interrelated with each other and effective functioning of all the dimensions is necessary for the successful implementation of health and safety culture at oil and gas environment. The six dimensions are-commitment, behaviour, awareness, adaptability, information and justness. 
The author has elaborated and explained each of the dimensions in a detailed manner in order to ascertain manner through which these six dimensions influence and determine the level of safety culture. Commitment is the first and foremost dimension in the said framework which reflect the extent to which managerial and other personnel of the oil and gas industry hold positive attitude towards ensuring and providing safety to members. The author has emphasised that this dimension of health and safety framework is concerned primarily with top managerial authorities of the oil and gas industry (Stranks 2006) [5].

This is so because author believed that commitment is mainly required by top management of oil and gas industry for implementing and maintaining safety culture. The commitment on the part of top management determines and influence the amount of resources allocated and provided by top management for implementing safety culture. The lack of commitment on the part of top management will prevent the implementation of health and safety culture. Therefore, gaining genuine commitment of top management for implementing safety culture in order to give high level of safety to employees is considered as essential prerequisite.

Behaviour is the second dimension of the health and safety framework according to Burke \& Clarks (2012) [6]. This dimension reflects attitude of employees and other organisation members towards implementing, maintaining and improving level of health and safety. It is said that it is the behaviour of employees and other organisation members of oil and gas companies that determines successful and effective implementation of safety culture. Besides, positive attitude and behaviour on the part of organisation members towards safety culture also prove beneficial in minimising chances of risks, danger, threats in the concerned business firms.

In today's environment of oil and gas industry instances of risks, threats, and dangers invite and increase the chance of legal litigation. In order to avoid the chances of legal litigation and portraying positive image on the world' map, it is necessary for the companies of oil and gas industry to depict positive behaviour and attitude towards the framework of health and safety culture (Burke \& Clarks 2012) [6].

Furthermore, awareness is the third dimension of the safety framework as per Walker (2007) [7]. As indicated, awareness reflect the level and extent to which personnel of oil and gas companies are aware and appreciate the fact that safety and wellbeing of ourselves and others is the implied duty of every business organisations irrespective of the level and scope of operations. This dimension of health and safety framework applies equally to both higher and lower authorities of oil and gas companies. This is so because dimension of awareness is conceptualised by top managerial authorities of the companies while it is implemented actually by employees and other staff members. The author has stated maintaining high degree of vigilance and surveillance regarding safety issues and concerns should be high priority area and concern for employees and managers at oil and gas companies (Walker 2007) [7].

Stranks (2010) [8] in concern with above defined safety framework has thrown light on the adaptability and information dimension. The willingness and commitment of employees and other organisation members towards learning and adapting new safety coping strategies and actions is measured by the adaptability dimension of safety framework. The failure to adhere with safety issues and concerns often result in various dangers and risks in the oil and gas environment. The extents to which such dangers and risks are taken seriously by the members of respective industry and level of willingness towards learning from past mistakes determine the successful implementation of safety culture (Stranks 2010) [8].

Information represent fifth dimension of the safety framework which bring attention towards right flow and distribution of information to the right people from the right source. Right flow of information is necessary to avoid any kind of miscommunication and taking rights actions at the right time. At many instances, miscommunication and deteriorated flow of information lead to hazardous situation at oil and gas firms. Therefore, authorities handling safety concerns and issues should ensure that employees and other staff members should receive information in the right manner for avoiding hazardous situations at the initial possible stage (Wien 2011) [9].

The author has also insisted that framework of safety culture in context of oil and gas environment should focus on the manner and approach with which employees and staff members react to the safety related information. It has been identified that many at times employees assign less importance to circulation and distribution of safety related information which makes functioning process of oil and gas firms more prone to hazardous situations. In this context, it is therefore recommended that employees and staff members should be encouraged to assign high importance to safety related information and react seriously towards such information (Burke \& Clarks 2012) [6].

Lastly, Collins (2009) [10] has identified and focused discussion on justness dimension of safety framework. This dimension is purely based and related with higher authorities of oil and gas firms. More specifically, just- 
ness indicates the extent to which safe behaviour and adherence with safety standards are encouraged, rewarded and motivated in the oil and gas companies. Besides, it also measures the extent to which unsafe behaviour and attitude of ignorance is punished and discouraged at the respective environment. The author believed that justness determines the future success and influence of safety culture in oil and gas companies. This is evident as rewards and encouragement make employees and staff members more motivated towards implementation and adherence of safety issues and concerns. Similarly, punishment and discouragement for depicting unsafe behaviour also develop a kind of fear among employees and can lead them in right direction (Collins 2009) [10].

Apart from above recognition of safety culture as a framework, Ridley (2012) [11] has studied and described concept of health and safety culture as a process containing eight elements as shown below (Figure 1).

The diagram has positioned the eight elements of safety culture in a circular form. All the elements of safety culture are related with each other and effective implementation of one influence success probability of other to a wide extent. Speegle (2012) [12] has studied and discussed the above elements of safety culture in context of environment of oil and gas industry. It can be analysed from the diagram that all the elements of the safety culture are based on strategic personnel of oil and gas companies. Like, the element of business priorities indicates objectives and goals of strategic authorities of respective business firms with regard to safety aspects and health issues. The risk and threatening issues are visualised by the strategic authorities before considering the decision of implementing safe and health oriented working environment (Speegle 2012) [12].

The author has also specified that risk perceptions vary significantly from one business firm to other. It is so because every business firm operate in a distinct industry and nature and kinds of risk factors depend on the industry in which the concerned business firms operate. For instance, risk perceptions are found to be high in case of oil and gas, manufacturing, leather, chemical, pharmaceutical industries more widely. As compared to it, business firms operating in financial services, telecommunication, and insurance sector are less prone and susceptible to risk perceptions. Therefore, risk perception of strategic personnel of manufacturing industries will be surely high as compared to that of service industries.

The proper analysis and visualisation of risk perceptions paved the path of considering the decision of implementing safety procedures. The perception of safety procedure element of the above diagram also affirms this fact. The strategic authorities of oil and gas firms visualise and perceive safety procedures in their minds before implementing it in actual practice. Such visualisation and perception is then portrayed in written form in the form of blueprint of safety procedures. The strategic authorities of business firms also consult and discuss such visualisation with specialised personnel and risk managers before finalising or arriving at final result (Iqbal et al. 2004) [13]. Such personnel will provide details regarding risky aspects and concerns of the proposed decisions.

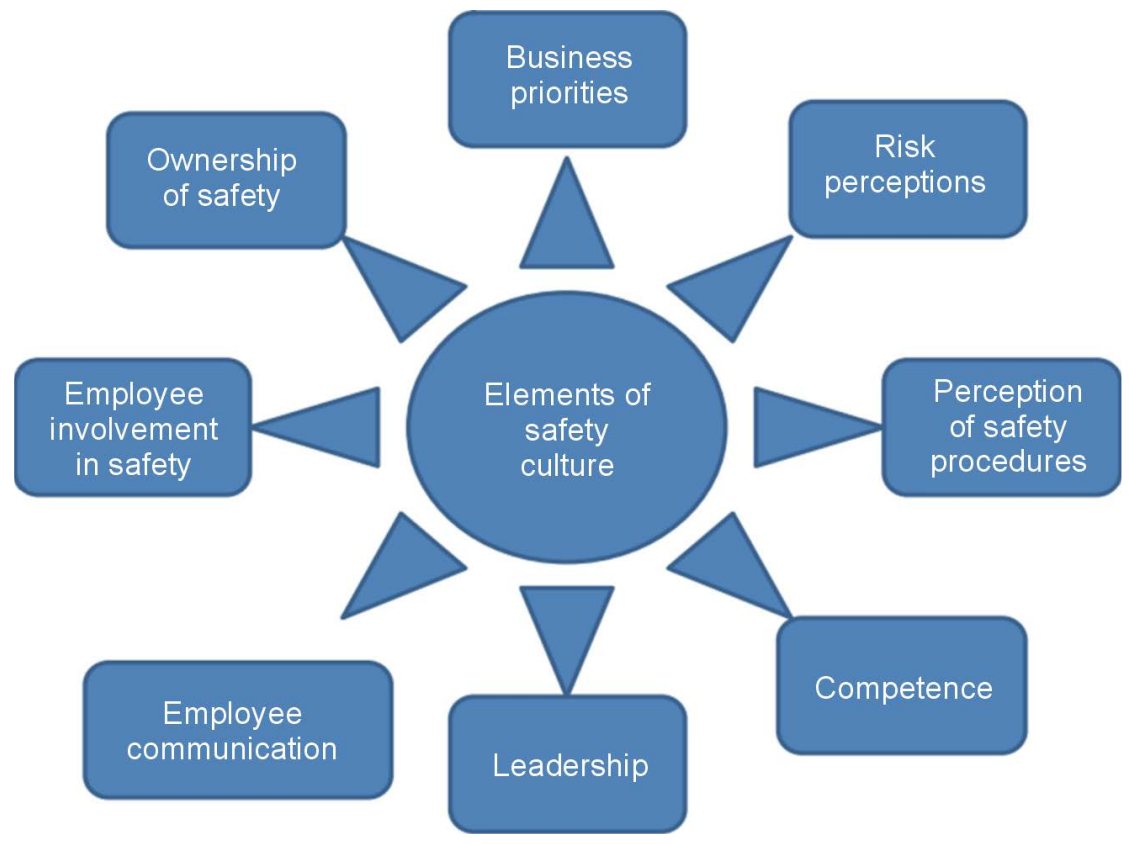

Figure 1. Elements of safety culture (Source: Ridley 2012) [11]. 
The prepared safety procedures are then implemented in actual practice with sound leadership skills and competence at oil and gas companies. Employee communication and their involvement in the implementation of safety procedures should also receive high importance by the leaders and concerned authorities as mentioned by Collins (2009) [10]. The ownership of health and safety culture appears to be the last element of the process. The author has specified that process of health and safety culture is owned mutually by all organisation members irrespective of their level and role. It is due to the fact that safety culture is implemented with mutual efforts of all members. No member can implement this process individually or without coordinating with others. Therefore, it would be judicious decision on the part of business firm to recognise the fact that safety culture is owned by all staff members (Collins 2009) [10].

The further exploration of health and safety culture has revealed that this concept can be understood in terms of an environmental set-up in oil and gas companies. More specifically, Barnett-Schuster (2008) [14] has researched the referring of the concept of health and safety culture as environmental settings and argued that recognising health and safety culture as environmental settings holds profound in current scenario of oil and gas industry. The author has explained this analysis and ascertained that phenomenon of health and safety culture demand a new, unique and creative atmosphere shared by all workforce.

Such environmental setting poses various appealing characteristics in it like high level of commitment towards safety and health issues, well defined safety procedures, customised and flexible working practices in accordance to sustainable health concerns, attitude of care and concern towards hazards and its perception, continuous learning approach through regular monitoring, analyses and reviewing. It is also said that such characteristics also act as yardsticks in measuring effectiveness of health and safety environment. The prevalence of such characteristics improves the possibility that concerned business firm pose healthier and safer environment and vice-versa (Barnett-Schuster 2008) [14].

Furthermore, Hughes \& Ferrett (2013) [15] have also tried to explain the concept of health and safety culture through outlining its three components with regard to oil and gas environment. In other words, Hughes \& Ferrett (2013) [15] have identified three components and presented study on these three components in an attempt to understand the concept of health and safety culture of oil and gas industry more minutely. These three components are psychological, situational and behavioural. In detailed terms, psychological component of health and safety culture deals with structural aspects of oil and gas companies. The structural aspects refer to policies, procedures, working patterns, management system, feedback and control system and many more. In all, the manner and approach of working and functioning of an organisation is dealt by situational component of health and safety culture.

Similarly, psychological component of health and safety culture deals with norms, beliefs, attitude, and perception of organisation members. And, behavioural component emphasises on set of behaviours, observations, self-reporting measures, etc prevailing among the business firms. All the three aspects hold high bearing on the initiation and implementation of safety norms and health concerns. The authors have also stated that all the three components provide an overall view of the prevailing and proposed health and safety culture. The health and safety culture tends to be an aggregate concept influences by all the three components stated above. The positive orientation of all the three components leads the researchers to believe that the concerned business firm can conceptualise the theme of health and safety culture effectively and vice-versa (Hughes \& Ferrett 2013) [15].

The theoretical concept of health and safety culture has been discussed in light of some academic models and theories. The model named as Swiss cheese model and HSE culture theory has been used for this purpose. Whittingham (2004) [16] stated that Swiss cheese model is understood as an accident causation model used for risk analysis and risk management purpose in the business environment. The model hold high profoundness in all industries and so is the oil and gas industry. It works on the assumption that accidents in case of oil and gas companies incur due to four kinds of failures prominently. Such four failures are organisational influence, unsafe supervision, preconditions for unsafe acts and unsafe acts themselves.

All the four failures are identified as a series of events resulting in the accidents. It can be depicted in Figure 2.

The depicted diagram states that accidents in oil and gas companies occur or results from a series of events. Such series of events take place at different time and points in the oil and gas companies. The diagram has positioned the safety system similar to the slices of Swiss cheese. The holes shown in the above diagram indicate the opportunities for failure that can result in the accidents if not prevented or handled by the layers. The slices of the Swiss cheese model represent different layers of the safety system and indicate more the layers of the safety 
system; the less will be the chance of an accident to happen. It is argued that when holes in the above layers of the Swiss cheese model line up, accident is sure to happen. Therefore, oil and gas companies should strive towards preventing such holes from line up through placing mor32e layers in the safety system (Whittingham 2004) [16].

HSE culture ladder theory also holds one of the significant theoretical frameworks in understanding and implementing the concept of safety culture. The theory has provided a guiding tool in the hands of global business firms for placing and implementing their safety culture and its practices according to Vinnem (2007) [17]. The HSE culture ladder theory provides five distinct ladders-pathological, reactive, calculative, proactive and generative. It can be presented as below Figure 3 .

The different ladders of the theory apply differently on business sectors depending upon the nature and kind of business process. This is so because intensity and chances of risks and threats vary and depends upon the nature and kind of business process to a wide extent. As per the Vinnem (2007) [17], the ladder seems applicable and profound in context of oil and gas environment is proactive i.e., fourth one. As the name indicates, proactive safety cultural practices at the oil and gas environment demands supervisors and managerial authorities to identify risky events, threatening actions, etc at the earliest possible level. The safety topics should form the topic of the meetings and themes of conversations at the working environment of oil and gas companies. The employees of the respective environment should not only be provided with the details of preventing accidents but also with the understanding that why the accidents happen. In other words, the factors, working procedures, process designs, etc pose any kind of dangers and threats should be conversed with the employees. In all, it is expected that

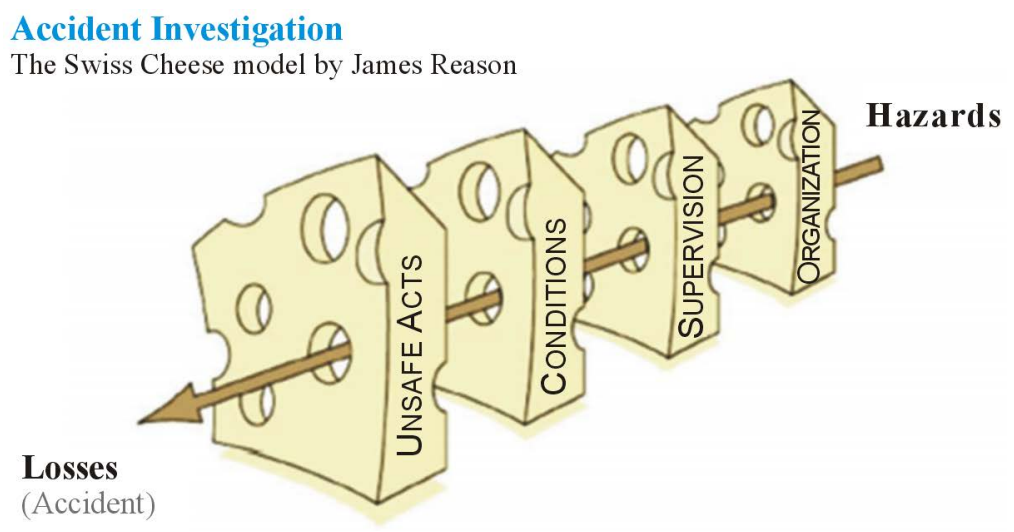

Figure 2. Swiss cheese model (Source: Whittingham 2004) [16].

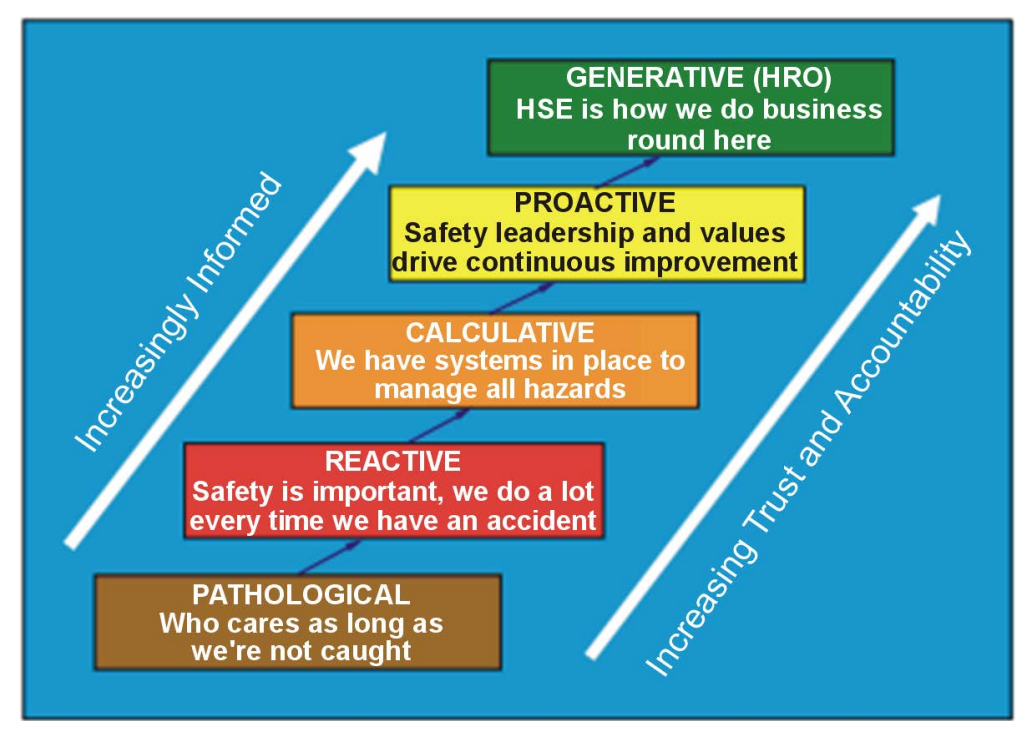

Figure 3. HSE culture ladder. 
safety authorities and personnel at the oil and gas companies should strive towards preventing risks and threats through cultivating safety culture and values among employees (Vinnem 2007) [17].

The trends of safety culture in regard to oil and gas environment is discussed in light of regulatory frameworks and regulatory bodies. Blunt \& Balchin (2002) [18] discussed the legislations and regulatory framework of oil and gas industry related to workplace safety and health standards. It is argued that regulatory frameworks of oil and gas industry have been made more comprehensive and integrated in today's scenario by the regulatory bodies. The regulatory bodies in context of health and safety culture are government representatives, industry spokespersons, law professionals, etc.

Such comprehensive set of legislations and regulatory frameworks has created positive impact on the health and safety standards. There are various manners through which legislations affected the implementation of health and safety culture like legislations provide and specify a level of safety standards which is necessary for every employer of the respective industry to conform and adhere. The minimum standards focusing on providing sustainable working environment to employees have increased. The legislations and enforcement mechanism of recent years also necessitate employers to draft and provide guidelines related to health and safety in an easy and understandable language (Blunt \& Balchin 2002) [18].

Cahill \& Kane (2010) [19] threw light on some specified regulatory frameworks like construction design and management regulations (CDM 2007) for construction oil and gas plant, converting or extending existing premises, demolishing buildings, etc. The regulatory framework require the oil and gas companies to allocate sufficient time and resources for finalising construction, site formation, appointing designers and contractors, etc. The competence and feasibility of all the activities and processes of oil and gas companies should be regularly monitored and assessed in order to avoid every possible hazards and risks (Cahill \& Kane 2010) [19].

Work at Height Regulations, another regulatory framework advocate the prevalence and implementation of best possible welfare facilities by oil and gas companies for their employees as per the Creighton \& Rozen (2007) [20]. Part 4 of the Work at Height regulations state that the contractors at the oil and gas companies are responsible for planning, managing, and monitoring their own work and as well as of those employees. The competence level of employees and all the staff members should be regulatory monitored in order to identify scope of improvements and arranging training sessions for improving said competence level. The health and safety guidelines of the regulation require every employee to assure and informed about their own competence level in order to cooperate effectively with their superiors and discharging entrusted roles in an effective manner (Creighton \& Rozen 2007) [20].

The Health and Safety work act applies in an equitable manner on all the business activities and processes according to Fishback \& Kantor (2007) [4] oil and gas environment is no longer exception to it and require adhering with the policies and guidelines of the Health and safety work act. The basic notion and guideline of the Health and safety work act is that every industry should be reasonably practical in devising and implementing safety culture and system. It is stated that every industry and concerned business firms should ascertain the impact of their working methodologies on employees, other people working at the sites, and general members of the public who may be affected by the work directly or indirectly.

Health and safety work act state that there are various parties in the safety culture who need to fulfil their own set of responsibilities and cannot be passed to someone else. Like, in general terms employers are under obligation of protecting employees from harm and negative impacts of business processes and activities. Employees, on the other hand are required to cooperate and coordinate with the employers on all the issues related with health and safety. Suppliers should ensure that the materials, equipments and machinery supplied by them are completely safe and in workable conditions and so on (Fishback \& Kantor 2007) [4].

\subsection{Nature of Oil and Gas Environment}

The nature of oil and gas environment is discussed in order to outline the kinds of hazards, risks and accidents prevail in the respective environment. The nature and kind of hazards and risks vary and differ in each environment according to Pichtel (2010) [21]. Oil and gas industry is confronted with various kinds of hazards and risks among which naturally occurring radioactive materials (NORM) is the significant one. NORM is used to refer the presence of various radioactive elements in the earth's crust and environment of oil and gas industry. Some such radioactive elements are uranium, thorium, radium, and radon that are present in the form of liquids and gases in the oil and gas working environment. 
The workers at the oil and gas companies are exposed to NORM through various external sources. At many times, NORM also enters into the body of the workers through inhalation, ingestions, absorption, or any other manner. The negative impact of such radioactive elements depends on the intensity and level of intake, duration of exposure, etc. The severe impact of NORM is being identified in the form of cancer among the workers of oil and gas industry (Pichtel 2010) [21].

Confined space is another physical hazard and risk identified specifically in case of oil and gas environment. According to Bonehill (2011) [22], confined space is an enclosed area on the site of oil and gas plant that appear big enough for a worker to enter and work in it. However, the design and structure of the confined space is such that it is not feasible and advisable for a worker to enter and work in it. But, there are various tasks necessitate workers of oil and gas companies to enter the confined spaces for inspecting, maintaining, monitoring, cleaning, repairing, etc which can complicate the health and safety concerns of workers. Some examples of confined spaces in oil and gas industry are storage tanks, boilers, pipelines, tunnels, etc.

The environment and physical setting of such confined spaces is too hazardous that it may result in the death of workers if they are not properly trained for entering and working in such spaces (Bonehill 2011) [22]. Besides, the other hazards and risks in the oil and gas industry identified in terms of hazardous noise, discharge of chemicals like silica, mercury, drilling fluids, hydrogen sulphide, etc.

Apart from the presence of hazardous elements, oil and gas industry is also considered as an environment of accidents and fatalities according to Boyd (2003) [23]. The oil drilling accidents and oil field accidents take place at large scale in oil and gas companies. The severity and duration of injuries in case of oil and gas industry is far worse than any other sectors and so is the recovery time. It is considered that avoidance of accidents in the oil and gas industry is almost inevitable and bound to happen. Some major forms of accidents in the oil and gas industry include explosions, mishaps, salt dome accidents, pipeline transportation accidents, storage problems, etc (Boyd 2003) [23].

\subsection{Analysing the Role of Organisation in Implementing Safety}

This holds another pertinent sub-section of the literature review and investigated and researched in light of various findings and research works. It is obvious that phenomenon of health and safety culture is implemented in the context of oil and gas companies. Therefore, it is also implied on the part of oil and gas companies to fulfil various kinds of roles for positioning itself as a safe and secure working point. Some of such roles are presented below:

\subsubsection{Assessing Internal and External Influences}

According to Harris (2002) [24], this assumes to be the most evident role of business organisation before and during the implementation of health and safety culture. Internal and external influences here refer to the factors and variables having potential to influence initiation and implementation of health and safety culture. It is not necessary that all the external and internal influences are negative in nature and will influence the culture of safety in negative terms. The internal and external influences can be regarded and understood in terms of positives and negatives as some create positive influence while some others create negative influence. In this context, the underlying sector has fostered individual analysis of each of the internal and external influences (Harris 2002) [24].

\section{1) Internal influences}

Management commitment, production/service demands, communications, competence, and employee representatives assume to be the main internal influences as shown in Figure 4.

Management commitment here indicates capability of senior managers of oil and gas companies to give appealing message to the workforce regarding health and safety issues according to Harris (2002) [24]. For this, senior managers and other authorities of the oil and gas companies should attain the level of desired performance of health and safety issues in order to demonstrate to employees what they actually want to achieve. It is also seen that employees develop negative thinking and perception regarding health and safety policies if they found senior managers and directors ignoring or discarding such policies and concerns. The management commitment is depicted when senior managers conduct health and safety inspections, regular meetings with health and safety committees, involving and solving cases of hazards and accidents seriously, etc.

Production/service demands reflect obligations on the part of oil and gas companies to establish balance between customers demand and employees actions. It is usually seen that higher authorities at the respective 


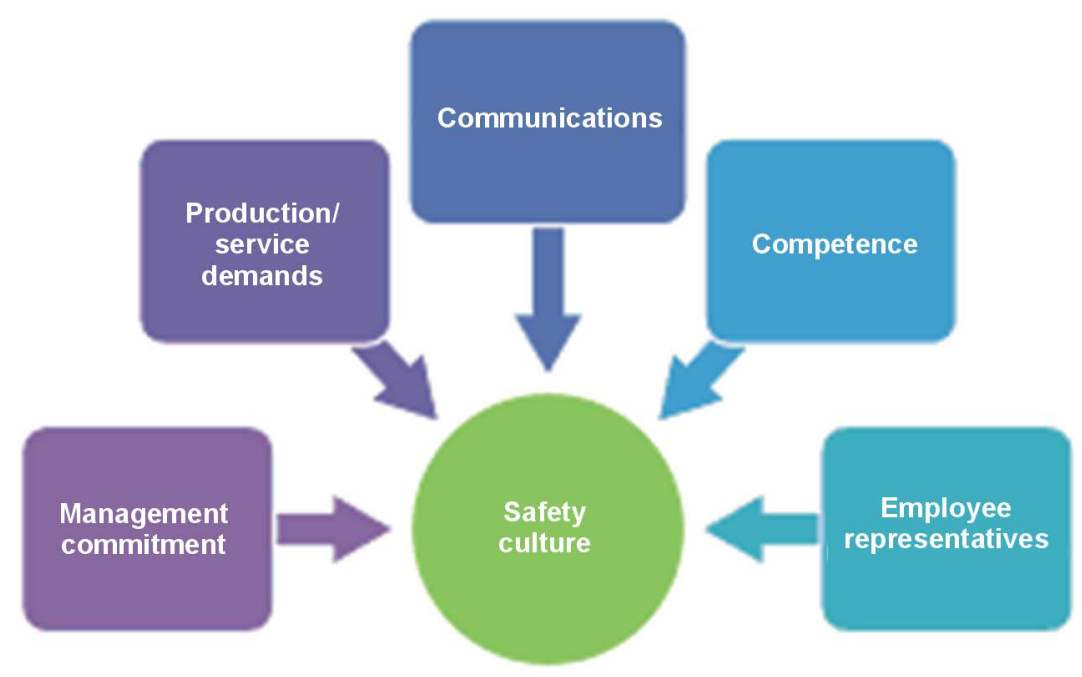

Figure 4. Internal influences on safety culture (Source: Harris 2002) [24].

companies instruct employees to agree or meet the customers demand at any cost. Such instructions by senior authorities create dilemmas for employees that whether they should ignore factors posing danger to their life at the time of fulfilling customer demands. It is implied on the part of organisation to save employees and customers from such crisis and dilemmas. At the same time, employees should also be guided and instructed to decide their priorities and take sensible and reasonable decision (Harris 2002) [24].

According to Bohle \& Quinlan (2000) [25], poor communication often creates confusions and conflicts among organisation's personnel. There is also possibility that poorly communicated health and safety procedures are often misunderstood and not followed by staff members. As a result, staff members depict a kind of lack of interest towards assigned duties which may cause accidents and serious injuries. It is necessary on the part of senior managers of oil and gas firms to have a policy of conducting regular discussion and meetings with staff members. This approach will enable to identify the problems and issues at the earliest possible level and recommending suitable solutions accordingly (Bohle \& Quinlan 2000) [25].

Competence, another significant internal influence deals with knowing and understanding what organisation members are doing and skills needed to make them more effective. Boyd (2003) [23] has also adhered with this fact and stated that this internal influence can play surprising role in making organisation effective enough. In this context, it is necessary for respective organisations to work on this internal influence i.e., competence.

The author has stated that competence cannot be brought in by the senior personnel of oil and gas organisations. Rather, it can be developed and nurtured among employees and staff members. Employees and staff members should be provided with an opportunity of interacting and conversing with senior authorities. Such conversation and interaction will enable employees and staff members to recognise their mistakes and learn new lessons. The concept of health and safety culture is an enduring one demands constant learning and commitment on the part of members. The respective organisations can materialise this fact through working upon competence level (Boyd 2003) [23].

Employee representation also accounts one of the significant internal influence need to be dealt by the respective organisations at regular intervals according to Creighton \& Rozen (2007) [20]. Oil and gas companies need to assign high importance to make employees enthusiastic and competent. This is so because enthusiastic and competent employees can make significant contribution in implementation of health and safety standards. Oil and gas companies should appreciate this fact and realise that staff members will carry out the assigned works and tasks with more precautions and safety when they are consulted and feel involved.

\section{2) External influences}

There are also various external influences need to be taken into account by the oil and gas companies in order to prepare and making health and safety culture more adaptive and flexible. Societal expectations, legislations and enforcements, economical conditions, stakeholders and trade unions account to be the major external influences have bearing on health and safety culture of oil and gas environment. It can also be represented in the form of diagram as shown in Figure 5. 


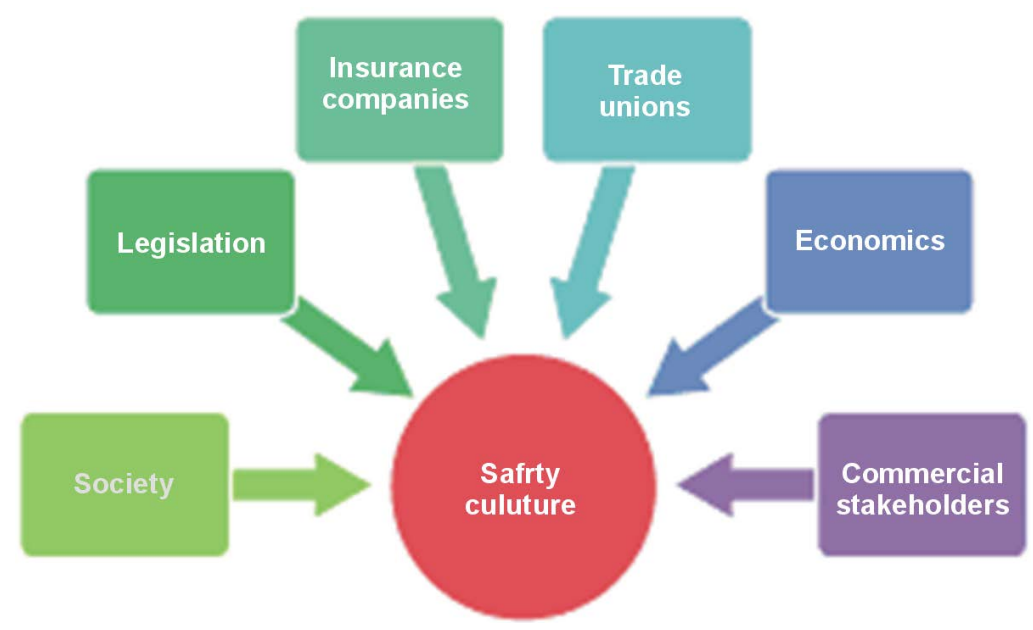

Figure 5. External influences on safety culture (Source: Creighton \& Rozen 2007) [20].

Societal expectations are highly variable term and tend to change with change in time and situations. The societal expectations vary significantly among the countries. Like, societal expectations are found to be high in case of wealthy and rich nations while low in case of underdeveloped and poor countries. For instance, the standards of safety have increased significantly in the UK over the last some years. A report presented by Karmis (2001) [26] highlighted that demand of cars have increased tremendously in UK in the beginning of $21^{\text {st }}$ century. The customers are expecting safe, comfortable, advanced and customised automobile products with less break downs and high performance now-a-days. Such demand has also driven the need of providing high standards of health and safety to employees simultaneously. In other words, the report has outlined the fact that high end societal expectations have great influence on workplace safety standards also (Karmis 2001) [26].

Cahill \& Kane (2010) [19] continued the discussion and emphasis on the impact of stakeholders of oil and gas industry of health and safety culture initiatives. The authors have mentioned that business firms operate in a dimension consisting varying set of internal and external stakeholders. Internal stakeholders comprise of employees, managerial personnel, directors, etc while external stakeholders include suppliers, government, investors, etc. Internal and external stakeholders are concerned not only with the profitability but also with the sustainability aspect of business. It has been found that oil and gas companies having high orientation towards health and safety aspects of customers and employers enjoy positive relations with stakeholders. Moreover, investors and suppliers of recent years depict interest in dealing with those organisations of respective industry having strict adherence towards health and safety measures. Therefore, it is necessary for organisation consider the influence and role of stakeholders in implementing health and safety culture (Cahill \& Kane 2010) [19].

Trade unions also account one of the major external influence regulating employees and their working behaviour. The empowerment and strong influence of human resource acts have made the trade unions of present world more powerful and capable. Similarly, trade unions of oil and gas environment demand high standards for preserving and protecting health and safety concerns of their employees (Iqbal et al. 2004) [13]. Such demand on the part of trade unions has created a kind of pressure and obligation on organisation regarding safety and health concerns.

\subsubsection{Health and Safety Training}

This is the second most evident role required to be fulfilled by oil and gas companies for ensuring success of health and safety initiatives. The provision of health and safety training will improve the level of awareness and understanding of organisation members towards safety and health issues according to Bonehill (2011) [22]. This role of organisation in context of health and safety culture has outlined in recent years for making people aware about risks and dangers associated with their assigned tasks and responsibilities. Besides, such training measures also inform and enable the members to learn control measures and safety procedures for preventing such risks and dangers.

As per Bonehill (2011) [22], oil and gas companies of today’s business world are facing legal obligation for 
conducting and organising health and safety training programmes. It is said that in addition to fulfilment of legal obligations, health and safety training programs also yield various direct and indirect benefits to concerned organisations. Some of such benefits include reduction in the instances of risks, dangers and threats and improvement in existing health status of employees. The training programs will also lead the organisations to experience reduction in the case of compensation claims and as well in absenteeism caused on account of health problems. Besides, the concerned organisations will also experience a dramatic improvement in the motivation and morale level of employees and staff members (Bonehill 2011) [22].

Karmis (2001) [26] focused discussion on the instances or situations demanding conduction of health and safety training measures. More specifically, concerned organisations are expected to organise and run health and safety training programmes in some situations and conditions according to Karmis (2001) [26]. It can also be understood in the manner that health and safety training needs and opportunities increased more in case of Figure 6.

The above mentioned diagram has stipulated the needs and opportunities of conducting health and safety training programs. Boyd (2003) [23] stated that when an employee is transferred or introduced to new job and process of oil and gas environment, need of health and training programs increased. This is so because new job bring simultaneous change in the set of duties and responsibilities and thus it is necessary for organisation to provide training to employees in order to fulfil new set of responsibilities in an effective manner. Similarly, the other instances demanding implementation of health and safety training programs include changes in working pattern, launching of new working equipments, adopting new set of technology, change in the employment status, vulnerability of working environment, and many more (Boyd 2003) [23].

\subsubsection{Sound and Effective Leadership}

This role of organisation has evolved from the fact that health and safety culture concept is visualised, developed and driven mainly by senior authorities of selected organisations according to Collins (2009) [10]. The business professionals hold the assumption that senior managers and authorities of concerned organisations are concerned primarily with health and safety issues. It is believed that workforce usually have less opportunity or scope to participate and materialise the concept of health and safety culture. The workforce is required to adopt and adhere with safety related procedures developed by senior personnel of organisation. In this context, need of sound and effective leadership has felt to drive workforce towards safety related procedures and mechanisms.

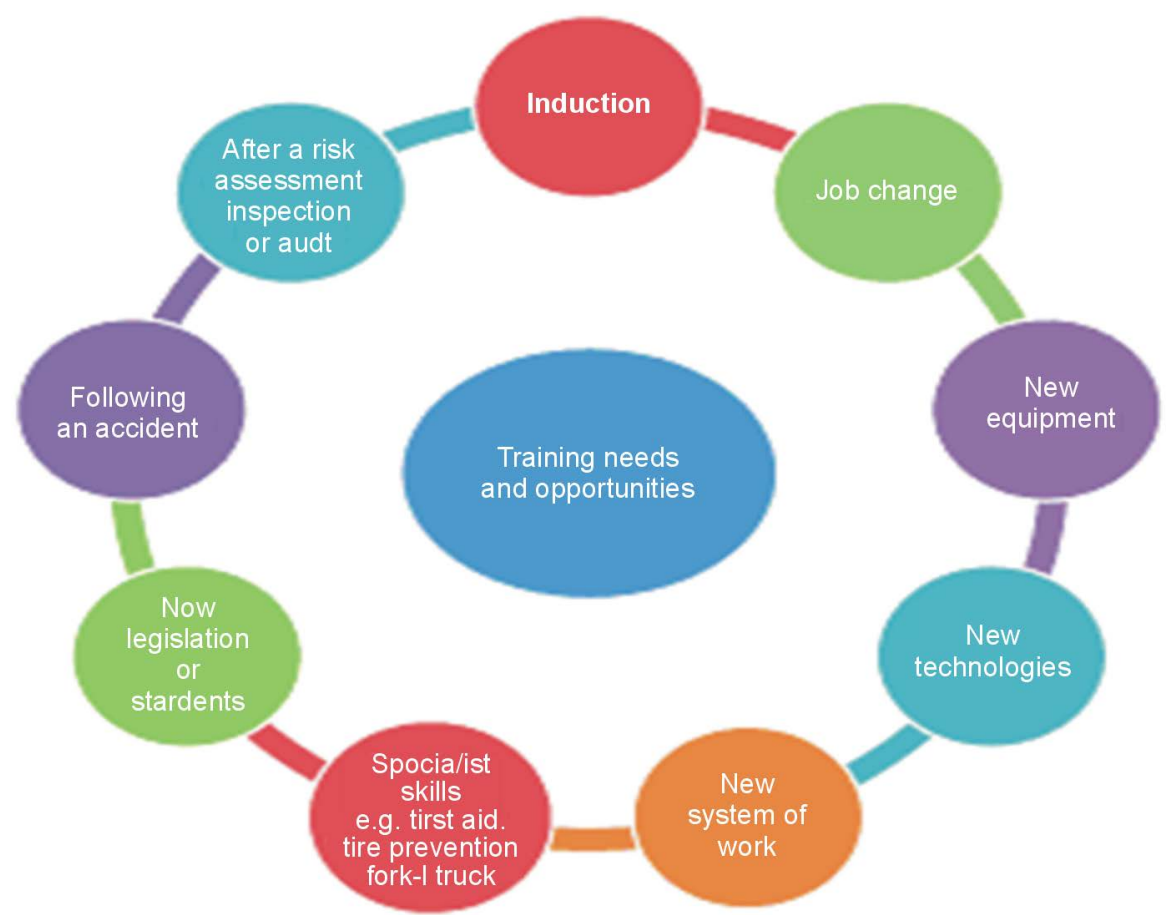

Figure 6. Training needs and opportunities (Source: Karmis 2001) [26]. 
This is so because sound and effective leadership on the part of oil and gas firms can play a significant role in motivating and encouraging workforce towards implementation of safety related procedures. There is possibility that workforce can take safety related procedures for granted and start ignoring them in their day-to-day working patterns. The personalised and effective leadership will minimise such chances through making workforce aware regarding significance of health and safety procedures and at the same time paving their path for implementation of such procedures (Collins 2009) [10].

In specific terms, effective leadership holds the potential of improving commitment level of members towards health and safety concerns, ensures the implementation of health and safety standards, cultivate health and safety culture as a long term visionary approach, provides regular assessment of health and safety status to identify areas of improvements, develops and recommends appropriate health and safety systems as and when needed, and so on.

\subsection{Challenges and Barriers in Implementing Safety Culture}

The implementation of safety culture in oil and gas environment is not an easy task according to Maslen (2008) [27]. There are various challenges confronted in the path of implementation of safety culture in the working environment of oil and gas industry. The first and foremost challenge relate with the lack of adequate support and commitment on the part of top management. The top management of various renowned oil and gas firms assigned less importance to the cultivation of safety culture and values among employees for the past many years. It was believed that there is no need of allocating resources for cultivating safety culture and values as the employees and personnel will learn it with the daily functioning and experience.

Such approach on the part of top management of the oil and gas industry acted as a major obstacle in implementing safety culture in some oil and gas companies. The implementation of safety culture requires adequate amount of financial, technological, and human resources. But, lack of appreciation of the importance of safety culture lead oil and gas industry to lag behind in the process of implementing safety culture (Maslen 2008) [27].

Ariss (2003) [3] threw light on the complexities of the safety operating system in the oil and gas companies. The author has stated that many oil and gas companies across the world have appreciated the importance of safety system and also implemented it. But, the complexity and difficulties faced by such business firms in implementing the safety system deter other firms from developing and implementing safety systems. One example related with Esso's Gas plant can be quoted in this context. The company has experienced a plant explosion in the Melbourne in the year 2005 on account of complexities in their safety management system. More specifically, the safety management system of the concerned firm was so complicated that the personnel and employees faced difficulty in handling and using it. Such difficulty has prevented the staff members and other personnel to understand the danger and threatening signs depicted by the system and thus results in huge explosion (Ariss 2003) [3].

Lack of employee involvement is also another challenging factor deterring the development and implementation of safety culture in oil and gas industry according to Quartey \& Puplampu1 (2012) [28]. The author has elaborated the reasons and factors leading employees of oil and gas industry to depict less involvement and participation in the implementation of safety culture. Such elaboration has outlined various pertinent facts and findings. One such fact related with the announcement of incentives on the basis of less number of accidents and injuries by the safety incentive program of some oil and gas firms. The employees are rewarded or announced with some kind of incentives if they report less number of injuries. Such rewards lead the employees of oil and gas industry to depict less involvement in using safety system for recording dangers and risks. This ignorance on the part of employees of respective industry results in heavy accidents and injuries in the longer time (Quartey \& Puplampu1 2012) [28].

The employees and other working personnel of oil and gas environment also reported that the safety culture evaluate their performance on the basis of the number of accidents and injuries. The employees and members who have showed less number of injuries and accidents are rewarded. But, there is no check on the process or mechanism adopted by the employees in preventing or minimising the cases of accidents. In other words, the outcome and results is the only criteria of performance evaluation. The process adopted by the employee in reducing the cases of accidents are not considered and rewarded. Such processes are rewarded only if it succeeds in avoiding accidents and injuries not otherwise which ultimately discourage employees from implementing safety culture and values (Speegle 2012) [12]. 


\section{Methodology}

The methodology section of the project aimed at presenting analyses of safety culture prevailing in the global oil and gas environment. The oil and gas environment is a quite wider topic and therefore an attempt is made to foster findings and analysis in light of some specific oil and gas companies. However, the study has targeted the entire industry and some firms are selected from it in order to ascertain trends, culture and practices of safety culture prevail in the oil and gas environment.

The main purpose behind selecting and analysing entire industry instead of specific business firms is to gain comprehensive view of the respective industry towards safety concerns. Secondly, the theme of the underlying project is general i.e., not based and related with single place, region and country. Thus, it seems difficult and impractical to select specific company or business firm based in any country in accordance with theme of the project. The findings and analysis are presented through desktop research i.e., through researching secondary sources of information available on such industries regarding health and safety issues in order to derive general conclusions regarding safety environment of oil and gas industry of the world.

A market research report named “Occupational disease hazards in the oil and gas industry” published in 2013 mentioned that oil and gas industry is recognised as a significant revenue earning industry across the world. The wide range of activities performed by the oil and gas industry has made it as one of the dynamic and flexible industry. It is obvious as products produced by the concerned industry is utilised in various commercial activities like leisure, transport, entertainment, etc. (Occupational disease hazards in the oil and gas industry. 2013) [29].

The report has stated that the oil and gas are utilised by various industries like automobile, chemical, aerospace, engineering, etc and thus widen the market tremendously. The wide usage of oil and gas products in different industries has also received increased attention towards safety and healthy working environment prevailing in the concerned industries. In this context, the report has researched and surveyed around 102 companies recognised as key and major players of oil and gas industry. Some of the prominent names are British Petroleum company, Chevron, Mobil Corp, Texaco, Enron, Petro Canada, Gulf Oil, Royal Dutch and many more (Oil and Gas Drilling Rig Hazards. 2013) [30].

The health and safety executives of the US under the guidance of government executives have undertaken research on rate and frequency on accidents in the Mobile Corp. The study was conducted in the year 2010 and ascertained that the rate of accidents and injuries in the concerned company was similar to those of other industries. In other words, the concerned company has not lagged behind in the race of accidents and injuries and reported high number of accidents like those happened in other industries. The statistics collected by the Health and Safety executives has outlined the fact that rate of injuries and accidents was significantly high in case of Mobile Corp. In oil and gas industry, intensity of injury and accident is measured in terms of 1 day injury, 2 day injury, 3 day injury and so on. The intensity and extent of pain is identified and recognised in accordance with it. In other words, more days of injury reflect higher intensity of pain and hazards and vice-versa (Healthy Workplaces Journey to Excellence: The Complete Guide. 2013) [31].

The overall statistics and figures of injuries have showed that around 9037 workers have suffered from injury and accidents in oil and gas industry across the world in 2010. The figure was quite high and thus necessitated the need of taking immediate appropriate actions for reducing instances of injuries and accidents in global oil and gas industry. It is advisable that industry experts, trade associations, and workforce groups to come and join their hands together for preventing workers from getting injured and preserving their health status.

After assessing status of health and safety culture in Mobil Corp, an attempt is made to assess the scenario of safety culture of Enron oil and gas (EOG). It is one of the largest oil and gas Exploration Company with proven resources headquartered in US. The various market research reports and press releases have been analysed for this purpose. One such report titled "Safety issues in the Enron oil and gas" (2012) [32] highlighted the fact that health and safety concerns cannot be ignored and has emerged as significant aspect in the company now-a-days according to Stranks (2006) [5]. The product's components, production processes, materials, etc create most evident impact on the workers health and safety in furniture industry.

The workers in the concerned company are not backed with strong professional skills and educational qualifications. In this context, it is the duty of their supervisors and managers to ensure that oil and gas exploration process create minimum negative impact on workers health. The major health hazards prevailing in the oil and gas exploration company include exposure to chemical, noises, poor handling of equipment, and unguarded 
machinery, poor management of waste and fire explosion (Stranks 2006) [5].

Perry (2003) [2] argued that workers working in the oil and gas industry are more prone to breathing and heart problems among the total workforce population. The global statistics has outlined the fact that workers of oil and gas industry are more prone to asthma, cancer, etc as they are more exposed to accidents and chemical hazards. It is assessed that workers and employees of oil and gas industry are getting more attacks of asthma and other breathing problems as compared to overall working population. The research studies have also evidenced the fact that materials and components are handled manually by the workers of the oil and gas industry. The pace of technological development and advancements is found at quite slow pace in the oil and gas industry as a result of which workers are required to handle materials and components manually. This situation makes them more susceptible to health injuries and assigns less importance to safety concerns (Perry 2003) [3].

\section{Discussions and Analysis}

The safety culture and system of Chevron Corporation has also been researched in an attempt to investigate safety and health issues of oil and gas environment more deeply. Chevron Corporation is a renowned multinational energy corporation engage in every kind of oil, gas and geothermal energy exploration, production, refining, etc. International Oil and Gas Workers' Federation (ITGLWF) works in around 110 countries through the network of various affiliated organisations. The federation works for many reasons like for assisting in policy formulation tasks and issues to the industries, protecting and safeguarding human rights, running wide array of education and development programs in developing countries for making workers more educated and organised and so on (ITGLWF. 2013) [33].

Monitoring, reviewing and assisting in the workplace health and safety aspects also account as one of the significant working area of ITGLWF. The recent findings published by ITGLWF regarding workplace health and safety issues asserted that oil and gas industry need reformatory measures for improving their working conditions. The international trade union movement has also affirmed this fact and stated that working conditions in such industries made the life of employees and workers more prone towards illness and other health hazards (ITGLWF. 2013) [33]. It has been mentioned that around 2 million men and women suffer from various kind of health hazards and accidents in these industries. The statistics presented by ITGLWF has showed that 270 million workers across the world suffer from occupational accidents in the oil and gas industry while 160 million workers suffer from occupational illness and diseases each year.

ITGLWF has outlined the need of strong government efforts for reducing instances of accidents and occupational diseases and implementing high standards of workplace safety. It is recommended that the concerned industry can only sustain and exist on the world's map through adhering with workplace safety standards. In this context, the federation has recommended government to enforce various standards and legislations for ensuring healthy and safe working environment in the oil and gas industry. The International Labour Conventions No.155 based on occupational health and safety measures, and No.161 on Health services is some such legislation advocating health and safety of workers at global working environment (ITGLWF. 2013) [33].

The US Centres for Disease Control and Prevention has collected data regarding a disease named Leukemia among the workers of oil and gas industry. It is believed that workers working in oil and gas industry and those residing near oil and gas exploration sites suffered from various kinds of health problems and diseases. The volunteers of the centres has collected data from the residents located in Kentucky nearby oil and gas exploration site and it was found that proportion of Leukemia in those residents was almost five times of the national average. Besides, the cases of lung cancer were also found at quite high rate among people exposed to working environment of oil and gas industry. Another study conducted in Sweden and Italy also presented the fact that cancer risks assume to prevail around 20\% - 50\% among workers working in oil and gas industry (Safety culture models. 2012) [34].

The continuous increase in the number of health hazards in oil and gas industry has forced government of various countries to discontinue oil and gas production, exploration and other related processes. For instance, government of European countries and US have announced and asked oil and gas producers to either discontinue their operations or shift their operations overseas. As a result, Bangladesh industry association has also declared that oil and gas industry is highly hazardous one and causing high threat to the health of people (Quartey \& Puplampu1 2012) [28]. The Bangladesh industry association stated that health of residents of their country is being threatened more severely by the oil and gas production and exploration process. The oil and gas industry 
of the country is not only posing threat to the health of the workers working there but also proving disastrous for general people. This is so because oil and gas sites discharge huge amount of chemicals and hazardous gases into atmosphere which in turn affect health of local residents.

In this context, one German study is also conducted in order to examine the impact of oil and gas exploration process on the employees. The study revealed that oil and gas exploration process creates most significant impact on the skin of employees. In other words, employees and workers of leather industries are more susceptible and prone to skin diseases and reaction because of their involvement in the oil and gas exploration process. It is asserted that oil and gas exploration process discharge various kinds of toxic chemicals like hexavalent chromium, which is considered a strong allergen substance. The employees get various kinds of skin reactions and diseases like Eczema on getting in contact with toxic chemicals. Besides, oil and gas conversion process of various oil companies is also posing threat to the lives of employees (Integrating Safety into Operations. 2012) [35].

Furthermore, a group named Blacksmith institute working in collaboration with research scholars, academicians, business professionals and governmental organisations also agreed the fact that health and safety measures employed at global business firms are proving less effective and inadequate one. The constant increase in the skin ulcerations and other chronic diseases has raised various questions on sustainability of working environment of leather industry (Integrating Safety into Operations. 2012) [35].

\section{Analysis}

The above discussion has indicated that situation of health and safety culture in the oil and gas environment across the world is not satisfactory and contains various performance gaps. The health and safety culture at oil and gas environment is still being recognised and treated as secondary and provided comparatively less importance. The global offshore environment also contains some such oil and gas companies having positive and appealing safety environment other than those discussed above. Thus, it also seems pertinent to foster an analysis of such oil and gas companies in order to gain an idea regarding trends of health and safety culture prevailing at such companies (Healthy Workplaces Journey to Excellence: The Complete Guide. 2013) [31]. Such analysis also provided a comprehensive analysis of the global oil and gas working environment to a wide extent.

There is numerous such oil and gas companies like Texaco, Petro-Canada, Royal Dutch, etc. depicted positive signs in regard to safety culture. In this context, an oil and gas company named Petro-Canada has been selected for assessing its health and safety culture. The Petro-Canada engage in the retail and wholesale marketing of the Suncor energy headquartered in the Calgary, Alberta. The Petro-Canada has operations in around 50 countries and serving wide array of petrochemicals, mining, oil and natural gas operations. The group is earning around 18 billion revenue each year from wide group of oil and gas operations. The operation philosophy of the Petro-Canada asserts that health, safety and environment assume to be its top most priority. It is ensured that people working in the Petro-Canada should feel as working in a safe and hygiene environment. The company's experience in dealing with defence, offshore, and remote sectors has provided an edge to recognise inherent risks and serious issues in a proactive manner (Integrating Safety into Operations. 2012) [35].

The proactive approach in the minds of strategic personnel of the company has enabled it to fulfil all set of obligations in an enriched manner. An integrated approach is being used by the Petro-Canada for risk analysis and threat avoidance purpose. The approach is introduced with the purpose of fulfilling statutory obligations, meeting client requirements, monitoring and complying with health and safety environmental practices. In all, the approach has provided a systematic approach for ensuring health and safety concerns to the Petro-Canada in today's business world. The approach has contributed in enabling the group to recognise as an industry leader embedded with "health and safety" values (Health, Safety \& Environment. 2013) [36].

British Petroleum Corporation is also renowned oil and Gas Company provides wide range of oil and gas exploration, production, refining, etc services to the retail and wholesale customers. The corporation appoints health and safety director for ensuring implementation of health and safety policy guidelines in an effective manner. The director ensures that workplace provides safe and healthy working conditions for employees and encourages them to yield their active involvement and support in working under such conditions. It is believed that activities of one employee influence and affect safety level of other employees to a wide extent and thus it is necessary to gain active involvement of all employees for having safe and hygiene environment (Corporate Social Responsibility Action. 2013) [37]. 
The commitment of health and safety standards at British Petroleum Corporation is quite high and extends to encouraging customers for making healthy choices along with providing health and safety culture to employees. In this context, standards related to health, safety, hygiene, welfare are formulated and implemented in light of legislative requirements and compliances. Implementation of health and safety systems along with proper guidance to employees for accomplishing assigned tasks also forms an essential component of health and safety culture at British Petroleum Corporation. Besides, providing regular training and supervision to employees, developing health and safety awareness, improving control system for controlling health hazards, regular consultation with employees, and many more also form part of health and safety culture at British Petroleum Corporation (Healthy Workplaces Journey to Excellence: The Complete Guide. 2013) [31].

\section{Conclusion and Recommendation}

On the basis of above discussion, it can be said that culture of health and safety appears quite strong and effectively implemented in case of some oil and gas corporations. There are still some oil and gas companies lacking somewhere in adhering and implementing with health and safety standards and concerns. The oil and gas exploration process at the oil and gas industry make the environment of concerned industry more susceptible to health hazards and safety issues.

In this context, a model is recommended for oil and gas industry as a whole to minimise and control the instances of health hazards and accidents. The model can be named as "incident-free and low-risk contracting model" aims at fostering health and safety culture in oil and gas environments. It is worth mentioning that implementation of model requires effective support and collaboration between trade unions, industry associations, employers, and government agencies. All these represent different stakeholders of the model and therefore their active involvement and participation is prerequisite for ensuring success of proposed model. The model will act as a supportive initiative for identifying areas of improvement in prevailing health and safety practices and providing tools to oil and gas companies for improving status of existing health and safety environments (Occupational health \& safety policy statement. 2012) [38].

The model is proposed to develop and implement with three-year vision in mind. It is believed that period of three years will adequate enough in reforming health and safety culture at oil and gas environments. The strategic objectives of the proposed model will be identified in terms of:

1) Fostering sound leadership

This will be the first and foremost goal of the proposed model. It is believed that sound and effective leadership on the part of oil and gas companies can only ensure success of any initiative. The model advocates implementation of "visible and felt" leadership for strengthening health and safety culture. More specifically, health and safety culture will be implemented by the people and for the people. Therefore, it is important for business leaders to lead people and staff members to realise that they are guided and directed in a personalised manner regarding health and safety concerns. Besides, the leaders also feel personally that health of the workforce should be protected and preserved at any cost. This attitude and behaviour on the part of leaders will surely imbibe a confidence and encouragement among workforce to adopt and adhere with health and safety issues. Other than this, leaders are also required to conduct regular auditing of health and safety standards for making them competent and effective, appointing health and safety committees, and specifying objectives for minimising accidents and dangers in working environment (Maslen 2008) [27].

2) Gaining management commitment

It is worth mentioning the every proposed initiative needs support and commitment from top management of the firm. Top management shares vision of the proposed initiative with entire workforce and articulate it in overall functioning philosophy. Moreover, top management also determine success of proposed initiatives through allocating and providing resources for implementing initiative in an effective manner. In this context, top management of the oil and gas companies will commensurate the proposed model in accordance with size and scope of their operations and thus will prepare policy and planning related to it. In all, it can be said that formulation of policy regarding proposed model, its implementation set-up and monitoring and reviewing can be done effectively through gaining adequate support and commitment from top management.

3) Gaining support and involvement of workforce

Workforce commitment is equally important like that of top management commitment. Top management can only prescribe and approve the implementation of proposed model, but the model will be actually implemented 
by workforce. For gaining involvement of workforce, they should be guided and motivated by leaders and supervisors. The effective guidance and supervision on the part of leaders and supervisors motivate workforce to adhere with health and safety standards. It is also believed that various business firms across the world facilitate consultation with employees' representatives in order to gain maximum possible involvement of workforce. In such consultations, senior managers and authorities are making workforce aware of the benefits and advantages of health and safety culture (Fishback \& Kantor 2007) [4].

4) Reducing risk instances

This forms the actual purpose for which proposed model will be implemented. The model will prepare and formulate an action plan for deciding priorities and preferences. It is necessary to have clear set of priorities and preferences in order to avoid confusions and vagueness. The action plan will outline and specify the health and safety issues targeted and handled by it in the coming time. The workforce will also be provided with clear set of criteria and arrangements for implementing the plan. The key challenges and issues posing highest threat to the said organisations will be targeted by the action plan at the earliest possible level. Along with it, it will also specify the means and mechanism for handling health hazards, assessing risk, and monitoring safety arrangements.

5) Accident reduction objective

Accidents are happening at high frequency in case of manufacturing business organisations now-a-days. The above discussed findings have also affirmed this fact that proportion of accidents in oil and gas companies is quite higher than those of other sectors. In this regard, a mechanism keeping a constant watch and monitoring on the instances of accidents is considered as necessity of present time. The underlying model will aim at providing such mechanism to the oil and gas environment through launching a consisting accident reporting system.

The consistent reporting system will aim at diagnosing and maintaining an accurate record and instances of accidents. Such reporting and diagnosis will assist oil and gas organisations in establishing a baseline and program for regulating instances of accidents. It is recommended that accident reporting system should also provide year-reduction target of accidents to oil and gas organisations. Such target should define reduction rate of accidents in percentage form along with guidelines and strategies for reducing instances of accidents. It is also believed that the target reduction rate of accidents should be challenging in order to compel organisations to attain it any cost but at the same time should be feasible and relevant (Fishback \& Kantor 2007) [4].

\section{Research Declaration}

I declare that this dissertation is completely my own work and any use of the others work has been properly acknowledged. I also confirm that this project has been conducted in accordance with the University's ethics guide.

I agree that the research work can be made available as a Reference Document to other students in the Department of Geography, Environment and Disaster Management.

\section{Acknowledgements}

I would like to thank Lord Almighty for making this research work possible and a successful one. I would also like to express my profound gratitude to my supervisor Justin Okoli for his guidance, assistance and at the same time for keeping me centred and able to remain focused on the goal I set for myself. I am also very grateful to my course director Dr. Babatunde Anifowose, and Augustine Ifebuegu for their support in making sure that this programme is a successful one.

Completion of this Master programme would not have been possible without the ceaseless prayers from my parents Prakasa Rao and Rani Prakash throughout this research project.

My sincere gratitude goes to my friends and well-wishers which are numerous to mention the names due to word count, thank you for your assistance, sharing knowledge, experience and time with me. And to everyone who have contributed in one way or the other to the success of this research but your name has not been mentioned, I say a big thank you to you.

\section{References}

[1] Lowe, G.S. (2008) The Role of Healthcare Work Environments in Shaping a Safety Culture. Healthcare Quarterly Journal, 11. 
[2] Perry, P. (2003) Health and Safety: Questions and Answers: A Practical Approach. Thomas Telford.

[3] Ariss, S.S. (2003) Employee Involvement to Improve Safety in the Workplace: An Ethical Imperative. American Journal of Business, 18.

[4] Fishback, P.V. and Kantor, S.E. (2007) A Prelude to the Welfare State: The Origins of Workers' Compensation. University of Chicago Press, Chicago.

[5] Stranks, J.W. (2006) The A-Z of Health and Safety. Thorogood Publishing.

[6] Burke, R.J., Clarke, S., et al. (2012) Occupational Health and Safety. Gower Publishing, Ltd.

[7] Walker, S. (2007) Health and Safety_Law and Practice. Straightforward co Ltd.

[8] Stranks, J. (2010) Health and Safety at Work: An Essential Guide for Managers. Kogan Page Publishers.

[9] Wien, G. (2011) Prevention of Major Accidents in the Oil \& Gas Industry. GRIN Verlag.

[10] Collins, S. (2009) Health and Safety: A Workbook for Social Care Workers. Jessica Kingsley Publishers.

[11] Ridley, J. (2012) Health and Safety in Brief. Routledge, London.

[12] Speegle, M. (2012) Safety, Health, and Environmental Concepts for the Process Industry. 2nd Edition, Cengage Learning, Boston.

[13] Iqbal, M., Soewardi, H., Hassan, A. and Che Haron, C.H. (2004) Ergonomic Study for Optimum Printing Workstation Using Factorial Experiment and Response Surface Methodology. Journal of Occupational Safety and Health, 1, 43-49.

[14] Barnett-Schuster, P. (2008) Fundamentals of International Occupational Health and Safety Law. Routledge, London.

[15] Hughes, P. and Ferrett, E. (2013) International Health and Safety at Work: For the NEBOSH International General Certificate. Routledge, London.

[16] Whittingham, R. (2004) The Blame Machine: Why Human Error Causes Accidents. Routledge, London.

[17] Vinnem, J.E. (2007) Offshore Risk Assessment: Principles, Modelling and Applications of QRA Studies. Springer, Berlin.

[18] Blunt, J. and Balchin, N.C. (2002) Health and Safety in Welding and Allied Processes. Woodhead Publishing, Sawston, Cambridge. http://dx.doi.org/10.1533/9781855737488

[19] Cahill, L.B. and Kane, R.W. (2010) Environmental Health and Safety Audits. Government Institutes.

[20] Creighton, B. and Rozen, P. (2007) Occupational Health and Safety Law in Victoria. Federation Press, Annandale.

[21] Pichtel, J. (2010) Waste Management Practices: Municipal, Hazardous, and Industrial. CRC Press, Boca Raton.

[22] Bonehill, J. (2011) Managing Health and Safety in the Dental Practice: A Practical Guide. John Wiley \& Sons, Hoboken.

[23] Boyd, C. (2003) Human Resource Management and Occupational Health and Safety. Psychology Press, Hove.

[24] Harris, M.K. (2002) Welding Health and Safety: A Field Guide for OEHS Professionals. AIHA.

[25] Bohle, P. and Quinlan, M. (2000) Managing Occupational Health and Safety: A Multidisciplinary Approach. Macmillan Education AU.

[26] Karmis, M. (2001) Mine Health and Safety Management. SME.

[27] Maslen, J. (2008) Driving at Work 2008: Special Report. Workplace Law Group, Cambridge.

[28] Quartey, S.H. and Puplampu, B.B. (2012) Employee Health and Safety Practices: An Exploratory and Comparative Study of the Shipping and Manufacturing Industries in Ghana. International Journal of Business and Management, 7, 81. http://dx.doi.org/10.5539/ijbm.v7n23p81

[29] Occupational Disease Hazards in the Oil and Gas Industry. (2013) [online] http://www2.worksafebc.com/i/posters/2013/WS_13_02.html

[30] Oil and Gas Drilling Rig Hazards. (2013) [online] http://ohsonline.com/articles/2009/07/01/oil-and-gas-drilling-rig-hazards.aspx

[31] Healthy Workplaces Journey to Excellence: The Complete Guide. (2013) [online] http://www.healthandsafetyontario.ca/HSO/media/WSPS/Resources/Downloads/HlthyWrkplcs_ComplGuide_FinalB.p $\underline{\text { df?ext }=. p d f}$

[32] Safety Issues in the Enron Oil and Gas. (2012) http://harrogate-news.co.uk/2012/09/25/safety-issues-in-the-english-manufacturing-industry/

[33] ITGLWF. (2013) [online] http://www.itglwf.org/lang/en/health-and-safety.html

[34] Safety Culture Models. (2012) [online] http://www.umweltbundesamt.de/nachhaltige-produktion-anlagensicherheit/anlagen/dokumente/oecd-cca-workshop/ii_ 
3_prae_hudson_netherlands.pdf

[35] Integrating Safety into Operations (2012) [online] http://www.ehs.ucr.edu/safety/systems/presentation\%20handout.pdf

[36] Health, Safety \& Environment (2013) [online] http://www.compass-group.com/cr-health.htm

[37] Corporate Social Responsibility Action (2013) [online] http://www.aramark.com/socialresponsibility/action/

[38] Occupational Health \& Safety Policy Statement (2012) [online]

http://www.compass-group.com/documents/OCCUPATIONAL_HEALTH_SAFETY_POLICY_STATEMENT_Dec ember_2012.pdf 
Scientific Research Publishing (SCIRP) is one of the largest Open Access journal publishers. It is currently publishing more than 200 open access, online, peer-reviewed journals covering a wide range of academic disciplines. SCIRP serves the worldwide academic communities and contributes to the progress and application of science with its publication.

Other selected journals from SCIRP are listed as below. Submit your manuscript to us via either submit@scirp.org or Online Submission Portal.
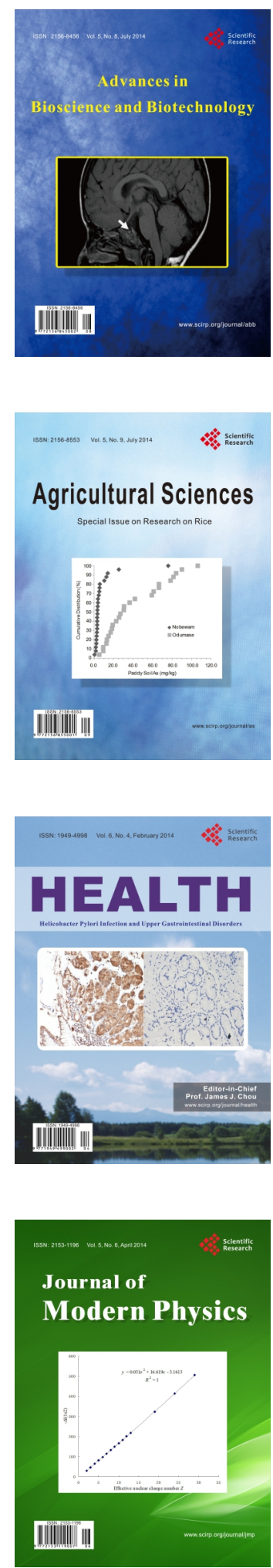
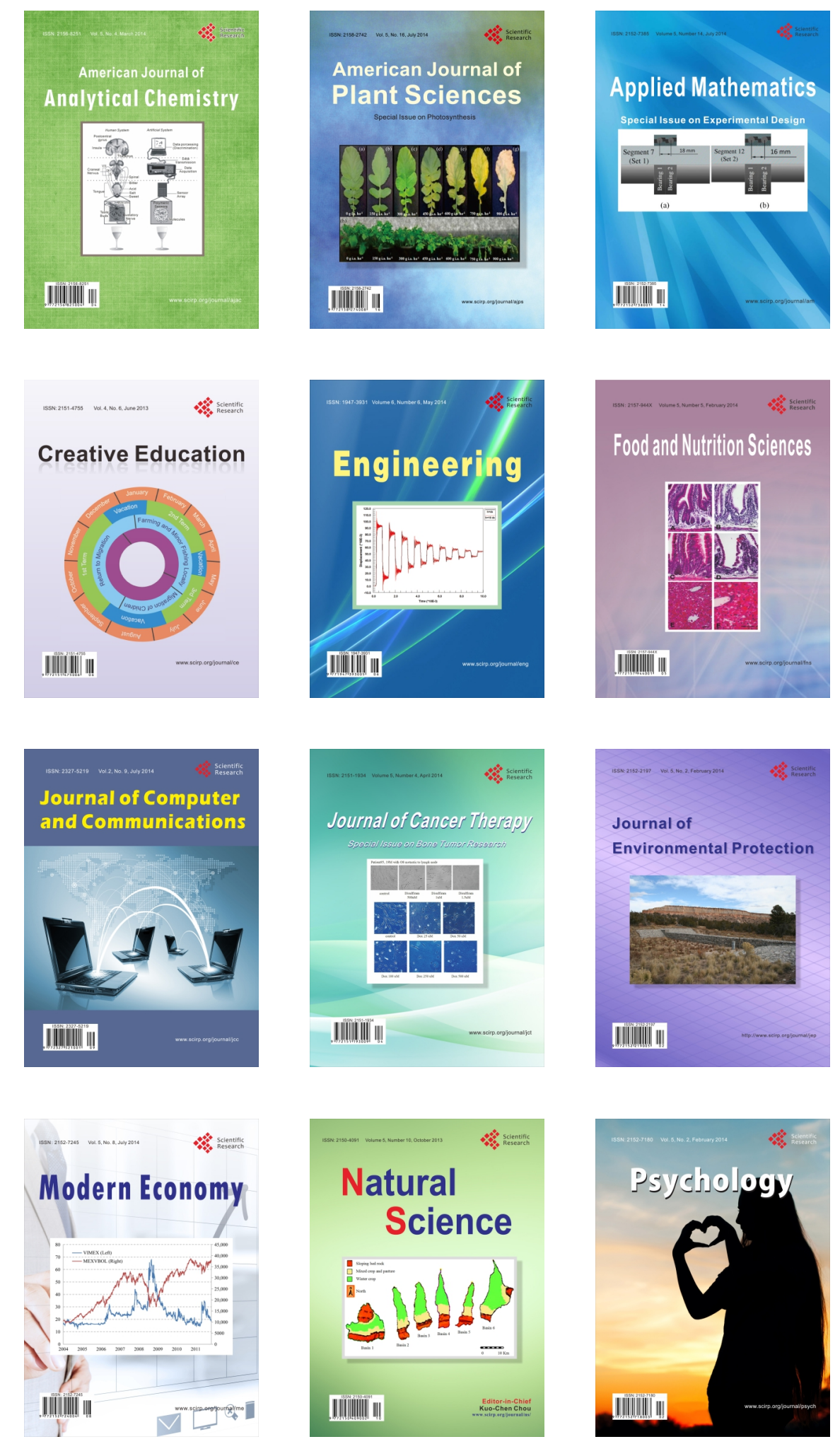